\title{
$\alpha 7$ nicotinic acetylcholine receptor in tumor-associated macrophages inhibits colorectal cancer metastasis through the JAK2/STAT3 signaling pathway
}

\author{
RUSHAN FEI, YUANWEI ZHANG, SAISAI WANG, TAO XIANG and WENBIN CHEN \\ Department of Colorectal Surgery, The First Affiliated Hospital, Zhejiang University School of Medicine, \\ Hangzhou, Zhejiang 310003, P.R. China
}

Received November 14, 2016; Accepted June 23, 2017

DOI: 10.3892/or.2017.5935

\begin{abstract}
Considerable evidence has implied that $\alpha 7$ nicotinic receptor subtypes play an important role in chronic inflammatory and neuropathic pain signaling. The aim of the present study was to determine the role of endogenous $\alpha 7 \mathrm{nAChR}$ signaling in tumor-associated macrophages (TAMs) in human colorectal cancer (CRC) metastasis and prognosis. $\alpha 7 \mathrm{nAChR}$ expression in primary tumor cells and adjacent stroma cells especially in TAMs in 51 CRC patients was observed. Using a human monocyte THP-derived macrophages (TMs) with $\alpha 7$ nAChR-siRNA knockdown $\left(\mathrm{TM} \alpha 7^{-/}\right)$and a CRC cell Transwell co-culture model, the migration and invasion of two CRC cells, LoVo and SW620, were determined. Western blotting was carried out to investigate the expres-

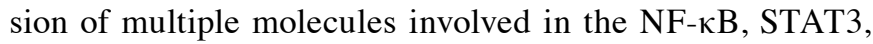
PI3K signaling pathways in mimic TAMs, i.e., TMs exposed to in-direct LoVo cell stimulation. A nicotinic $\alpha 7$ receptor antagonist $[\alpha$-bungarotoxin $(\alpha$-Btx) $]$ and three pharmaceutical inhibitors: AG490 (JAK2/STAT3 inhibitor), LY294002 (PI3K inhibitor) and Bay 11-7082 (NF- $\mathrm{B}$ inhibitor) were applied to evaluate whether these signaling pathways were associated with the enhanced migration of CRC cells when co-cultured with $\alpha 7 \mathrm{nAChR}$ knockdown TMs. The results revealed that the expression of $\alpha 7 \mathrm{nAChR}$ in TAMs differed in patients. However, CRC patients who had a high incidence of hepatic metastasis showed no or low expression of $\alpha 7 \mathrm{nAChR}$
\end{abstract}

Correspondence to: Dr Wenbin Chen, Department of Colorectal Surgery, The First Affiliated Hospital, Zhejiang University School of Medicine, 79 Qingchun Road, Hangzhou, Zhejiang 310003, P.R. China

E-mail: cwbin@hotmail.com

Abbreviations: CRC, colorectal cancer; $\alpha 7 \mathrm{nAChR}, \alpha 7$ nicotinic acetylcholine receptor; TAMs, tumor-associated macrophages

Key words: $\alpha 7$ nicotinic acetylcholine receptor, tumor-associated macrophage, colorectal cancer, metastasis, signaling pathway in TAMs. TMs with $\alpha 7 n$ AChR-siRNA knockdown (TM $\alpha 7^{-/-}$) significantly enhanced the migration and invasion of the two CRC cell lines LoVo and SW620. $\alpha 7$ nAChR knockdown in TMs significantly downregulated phosphorylation of STAT3, PI3K p85 and NF-кB p65 after co-culturing with LoVo cells. Inhibition of JAK2/STAT3 prevented the TM $\alpha 7^{-/-}$-enhanced migration of LoVo cells. $\alpha 7 \mathrm{nAChR}$ expressed in TAMs in human CRC patients plays an important role in preventing metastasis and could be a prognostic marker in CRCs, which may be regulated by the JAK2/STAT3 signaling pathway.

\section{Introduction}

Substantial evidence suggests that stromal cells including inflammatory cells and fibroblasts can interact with adjacent cancer cells (1). The inflammatory cells such as macrophages, neutrophils, and lymphocytes exist in the tumor microenvironment and play an indispensable role in cancer progression. Macrophages found in close proximity or within tumor masses are indicated as tumor-associated macrophages (TAMs) $(2,3)$. Since pro-inflammatory macrophages have pronounced antitumor activity and are cytotoxic to tumor cells, TAMs are believed to play a pivotal role in preventing tumor development (4). Nevertheless, persistence of an inflammatory response appears to be detrimental and causes cancer initiation and/or progression probably through the generation of mutation-inducing reactive oxygen species and nitrogen-free radicals (5). Indeed, in some types of carcinomas, TAMs appear to not only fail to kill tumor cells but also contribute to tumor progression by promoting cell proliferation, tumor growth, angiogenesis and metastasis $(6,7)$. Whether and how TAMs play an important role in colorectal cancer (CRC) remains controversial. According to an early study, TAMs may act as one line of defense against malignant cells in CRC patients (8). TAMs infiltrating at the invasive front in colon cancer are associated with improvement in both hepatic metastasis and overall survival (9). In contrast, Ishimaru et al found that TAMs induce the expression of osteopontin contributing to metachronous liver metastases in CRC (10). However, it has been reported that both CD169- and CD40-positive macrophages are associated with a favorable prognosis in colorectal carcinoma patients $(10,11)$, indicating that TAMs 
Table I. Clinical and pathological features of the examined patients.

\begin{tabular}{|c|c|c|c|c|}
\hline \multirow[b]{2}{*}{ Patient characteristics } & \multirow[b]{2}{*}{ All patients $(\mathrm{n}=51)$} & \multicolumn{2}{|c|}{ Patients with $\alpha 7 \mathrm{nAChR}$ (TAM/stroma) } & \multirow[b]{2}{*}{ P-value } \\
\hline & & Grade $\leq 1(n=33)$ & Grade $\geq 2(n=18)$ & \\
\hline \multicolumn{5}{|l|}{ Sex } \\
\hline Male & 32 & 21 & 11 & 1.00000 \\
\hline Female & 19 & 12 & 7 & \\
\hline $\begin{array}{l}\text { Mean }( \pm \mathrm{SD}) \text { age at } \\
\text { diagnosis (years) }\end{array}$ & $65 \pm 13.5$ & $60 \pm 13.4$ & $57 \pm 14.0$ & 0.4555 \\
\hline \multicolumn{5}{|l|}{ Tumor metastasis (no.) ${ }^{\mathrm{a}}$} \\
\hline Dukes' A or B or C & 37 & 20 & 17 & 0.0101 \\
\hline Dukes' D & 14 & 13 & 1 & \\
\hline 5 -year survival $(\%)^{\mathrm{a}}$ & 50.98 & 42.42 & 77.77 & 0.0201 \\
\hline
\end{tabular}

TAM, tumor-associated macrophage.

have protective potential in colon cancers and may serve as a novel therapeutic target.

Nicotinic acetylcholine ( $\mathrm{ACh}$ ) receptors are a family of integral membrane proteins, which function as ligandgated, pentameric ion channels responding to the binding of $\mathrm{ACh}$, a neurotransmitter. In humans, 16 different subunits of nicotinic ACh receptors $(\alpha 1-7, \alpha 9-10, \beta 1-4, \delta, \varepsilon, \gamma)$ are expressed on non-neuronal cells both within and outside the nervous system. The non-neuronal nAChRs have considerable implications for several diseases induced by tobacco usage such as cancers and cardiovascular disease through the non-neuronal nAChR signaling pathway (12). For example, AChRs, particularly, $\alpha 7 \mathrm{nAChR}$, can mediate nicotinedependent upregulation of proliferative and survival genes that contribute to the growth and progression of lung cancer cells in vitro and in vivo (13-16). $\alpha 7 \mathrm{nAChR}$ is an important factor in the regulation of cell signaling, which is expressed in many different non-neuronal cells such as vascular and brain endothelial cells, bronchial epithelial cells, keratinocytes, astrocytes, synoviocytes, thymocytes, lymphocytes, bone marrow cells, monocytes, macrophages and microglia (17-19). An $\alpha 7 \mathrm{nAChR}$ unbalance may be involved in different diseases such as Alzheimer's, Parkinson's and cancer (20). $\alpha 7 \mathrm{nAChR}$ is also an important component of the underlying mechanism that regulates the anti-inflammatory efficacy of the cholinergic anti-inflammatory pathway $(21,22)$. It has also been reported that $\alpha 7 \mathrm{nAChR}$ silencing inhibits lung cancer proliferation (23). Thus, $\alpha 7 \mathrm{nAChR}$ offers rational bases to develop new drugs and therapeutic strategies for different diseases including cancers.

Recently, it was reported that nicotine increases cell proliferation and inhibits apoptosis through the activation of the $\alpha 7 \mathrm{nAChR} / \mathrm{ERK} / \mathrm{AKT}$ pathway in human colon carcinoma cells (24). Our laboratory also found that nicotine enhances the invasion and metastasis of human CRC cells through the nicotinic ACh receptor downstream p38 MAPK signaling pathway (25). Inhibition of $\alpha 7 \mathrm{nAChR}$ induces apoptosis in non-small cell lung carcinoma and may provide a feasible rationale for preventing the progression of head and neck squamous cell carcinoma (HNSCC) $(26,27)$. Recently, Salaga et al reported that encenicline, an $\alpha 7$ nicotinic $\mathrm{ACh}$ receptor partial agonist, decreased macrophage infiltration in the colon and improved experimental colitis in mice (28). However, although $\alpha 7 \mathrm{nAChR}$ has been proposed as a pharmacological target for inflammation in different human diseases including cancers, few studies on how $\alpha 7 \mathrm{nAChR}$ is expressed in TAMs in human $\mathrm{CRC}$ have been reported. It is also unclear whether $\alpha 7 \mathrm{nAChR}$ expressed in TAMs is involved in the prognosis of colorectal carcinoma. Here, we examined the expression of $\alpha 7 \mathrm{nAChR}$ in TAMs in CRC patients and found that high expression of $\alpha 7 \mathrm{nAChR}$ in TAMs was associated with low incidence of hepatic metastasis. We revealed that human monocyte THP-derived macrophages with $\alpha 7 n$ AChR knockdown significantly enhanced invasion and migration of CRC cells in a Transwell co-culture model, which probably acted through the JAK2/STAT3 signaling pathway.

\section{Materials and methods}

Patients. Fifty-one consecutive cases of colorectal carcinomas used for the study were recruited from the patients who had undergone curative resection at the First Affiliated Hospital of Zhejiang University (Zhejiang, China) between May 2005 and May 2011. Inclusion criteria were a histological diagnosis of colorectal adenocarcinoma without chemotherapy or radiation therapy and without blood transfusions before surgery. Follow-up examinations were performed in March of 2016 by the first author. The telephone follow-up included the quality of life, progression of disease and survival time. The study was approved by the Human Research Ethics Committee of the First Affiliated Hospital of Zhejiang University (Zhejiang, China) and formal consent was obtained from all the patients prior to participation.

The clinical and pathological data of the patients included in the study are shown in Table I. For histopathological examination with hematoxylin and eosin, all surgical specimens were freshly cut and tissue samples were obtained from the primary tumors from the area of maxi ding in paraffin wax. We recorded the tumor size, Dukes' classification (UICC, 2002), number of lymph nodes involved and the stage of the disease. The histological grade of the tumors consisting of high-grade 
A

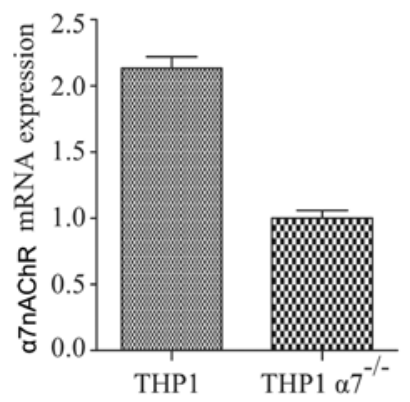

Figure 1. $\alpha 7 \mathrm{nAChR}$ is knocked down in THP-1 derived macrophages (TMs) The (A) mRNA and (B) protein expression level of $\alpha 7 \mathrm{nAChR}$ in TMs was determined by RT-qPCR and western blotting, respectively.

(poorly and undifferentiated) and low-grade (well and moderately differentiated) was evaluated following the two-tiered grading system recommended by Compton et al (29).

Immunohistochemical staining and macrophage staining with $\alpha 7 n A C h R$ evaluation. To understand the association between $\alpha 7 \mathrm{nAChR}$ in TAMs and CRC, immunohistochemical (IHC) staining was performed on consecutive freshly cut, formalin-fixed, paraffin-embedded tissue sections. Mouse anti-human monoclonal antibody against CD68 (M0178; Dako Corporation, Carpinteria, CA, USA), a marker of macrophages or a mouse monoclonal antibody against the nicotinic receptor $\alpha 7$ ( $\alpha 7 \mathrm{nAChR}$, ab23832; Abcam, Cambridge, UK) was applied to stain two sequential sections, respectively by using EnVision+ Dual Link kit (Dako) according to the manufacturer's instructions. Antigen was developed with peroxidase and 3,3'-diamino-benzidine tetrahydrochloride (brown reaction product). The tissue sections were counterstained with hematoxylin (Zymed Laboratories Inc., San Francisco, CA, USA) and mounted in non-aqueous mounting medium. The macrophage staining with $\alpha 7 \mathrm{nAChR}$ was classified into 5 grades as follows - grade 0: 0 macrophages/high power field (HPF); grade 1: <3 macrophages/HPF; grade 2: 3-5 macrophages/HPF; grade 3: 5-10 macrophages/HPF; grade 4: >10 macrophages/HPF (30).

Cell culture. LoVo cells (ATCC CCL-229 ${ }^{\mathrm{TM}}$ ) and SW620 cells (ATCC CCL-227 ${ }^{\mathrm{TM}}$ ), both derived from human colon adenocarcinoma metastases were grown in RPMI-1640 medium containing $10 \%$ heat-inactivated fetal bovine serum (FBS), $2 \mathrm{mM}$ glutamine, $50 \mathrm{U} / \mathrm{ml}$ penicillin and $50 \mu \mathrm{g} / \mathrm{ml}$ streptomycin. Human monocytic leukemia cell line THP-1 cells from American Type Culture Collection (ATCC, catalog no. TIB-202 ${ }^{\mathrm{TM}}$ ) were cultured in RPMI-1640 medium containing $10 \% \mathrm{FBS}, 2 \mathrm{mM}$ glutamine, $50 \mathrm{U} / \mathrm{ml}$ penicillin, $50 \mu \mathrm{g} / \mathrm{ml}$ streptomycin and $0.05 \mathrm{mM} \beta$-mercaptoethanol $(\beta-\mathrm{ME})$ at $2-8 \times 10^{5}$ cells $/ \mathrm{ml}$. The cells were maintained at $37^{\circ} \mathrm{C}, 95 \%$ humidity and $5 \% \mathrm{CO}_{2}$. Cell viability was determined by trypan blue exclusion assay. All the cell culture reagents were purchased from Invitrogen (Shanghai, China).

Establishment of human monocyte THP-1-derived macrophage (TM) cell lines. Stable $\alpha 7 \mathrm{nAChR}$ knockdown human monocyte THP-1 cell lines were generated by transfection of the cells with $\alpha 7 n$ AChR-siRNA expression plasmid Lenti-X followed by puromycin selection, which was provided by Jinsirui Biological Technology Ltd. (Nanjing, China). The following shRNA sequence was used for knockdown of human a7nAChR: 5'-ggatccGATCACTATTTACAGTGGAA TTTCAAGAGAATTCCACTGTAAATAGTGATCTTTTTT CCATGGtctaga-3'. THP-1 cells stably bearing a mock $\alpha 7 \mathrm{nAChR}$ expression plasmid (Jinsirui Biological Technology Ltd.) were used as control cells. Both RT-PCR and western blot analysis confirmed that the two THP-1 cell lines were very stable without or with expression of $\alpha 7 \mathrm{nAChR}$ at both mRNA and protein levels (Fig. 1).

The two THP-1 cell lines grown in RPMI-1640 medium were stimulated with $20 \mathrm{ng} / \mathrm{ml}$ phorbol 12-myristate 13 -acetate (PMA; Sigma-Aldrich, St. Louis, MO, USA) for $48 \mathrm{~h}$ to induce the cells to differentiate into macrophages. After removing non-attached cells by washing three times with serum-free RPMI-1640 medium, the adherent macrophages were considered as $\mathrm{TM} \alpha 7^{-/-}$and $\mathrm{TM}$, respectively and were used for the following experiments.

Cancer cell invasion and migration assay. Cell invasion and migration assays were carried out using modified Boyden chambers consisting of Transwell $(8-\mu \mathrm{m}$ pore size; Corning Costar Corp., Cambridge, MA, USA) membrane filter inserts in 24-well tissue culture plates. For the invasion assay, the upper surfaces of the membranes were coated with $100 \mu \mathrm{l}$ of Matrigel (BD Biosciences, San Jose, CA, USA) at $37^{\circ} \mathrm{C}$ for $6 \mathrm{~h}$ and then placed into 24-well tissue culture plates which were plated with $\mathrm{TM}^{\mathrm{T}} 7^{-/-}$and TM cells $\left(2 \times 10^{5}\right)$ in $500 \mu \mathrm{l}$ medium containing $10 \%$ FBS. SW620 or LoVo cells $\left(5.0 \times 10^{5}\right)$ in $200 \mu 1$ serum-free RPMI-1640 medium were added to each Transwell chamber and allowed to invade toward the underside of the membrane for $36 \mathrm{~h}$ for LoVo cells and $24 \mathrm{~h}$ for SW620 cells. Non-invading cells were removed by wiping the upper side of the membrane with a cotton swab and the invaded cells were fixed with ice-cold methanol. Then the inserts were stained with $0.5 \%$ crystal violet in $20 \%$ ethanol for $30 \mathrm{~min}$. The cells that invaded to the underside of the membrane were quantitated by cell counting under a light microscope in four predetermined fields at a magnification of $x 400$. For the migration assay, the cell cultures and treatments were the same as those of the invasion assay except that there was no Matrigel in the upper surfaces of the membranes.

To investigate the effects of signaling pathway inhibitors on TM $\alpha 7^{-/-}$-enhanced migration of LoVo cells: TM cells $\left(2 \times 10^{5}\right)$ in $500 \mu \mathrm{l}$ of medium in 24-well tissue culture plates were treated with or without $\alpha$-bungarotoxin ( $\alpha$-Btx, a potent nicotinic $\alpha 7$ receptor antagonist; Sigma-Aldrich) at $100 \mathrm{nM}$ for $6 \mathrm{~h}$. After being washed with PBS three times, the TM cells were further treated with or without three signaling pathway inhibitors: AG490 (JAK2/STAT3 inhibitor, $20 \mu \mathrm{M}$ ), LY294002 (PI3K inhibitor, $5 \mu \mathrm{M}$ ) and Bay 11-7082 (NF- $\kappa \mathrm{B}$ inhibitor, $2 \mu \mathrm{g} / \mathrm{ml}$ ) for 1 h. AG490, LY294002, and Bay 11-7082 were purchased from Beyotime Institute of Biotechnology (Shanghai, China). After being washed with PBS 3 times, $500 \mu \mathrm{l}$ of medium containing $10 \%$ FBS was added into the lower chamber and 5.0x $10^{5}$ LoVo cells in $200 \mu \mathrm{l}$ of serum-free RPMI-1640 medium were added to each Transwell chamber for $36 \mathrm{~h}$. The cell migration assay was the same as the procedure aforementioned. 

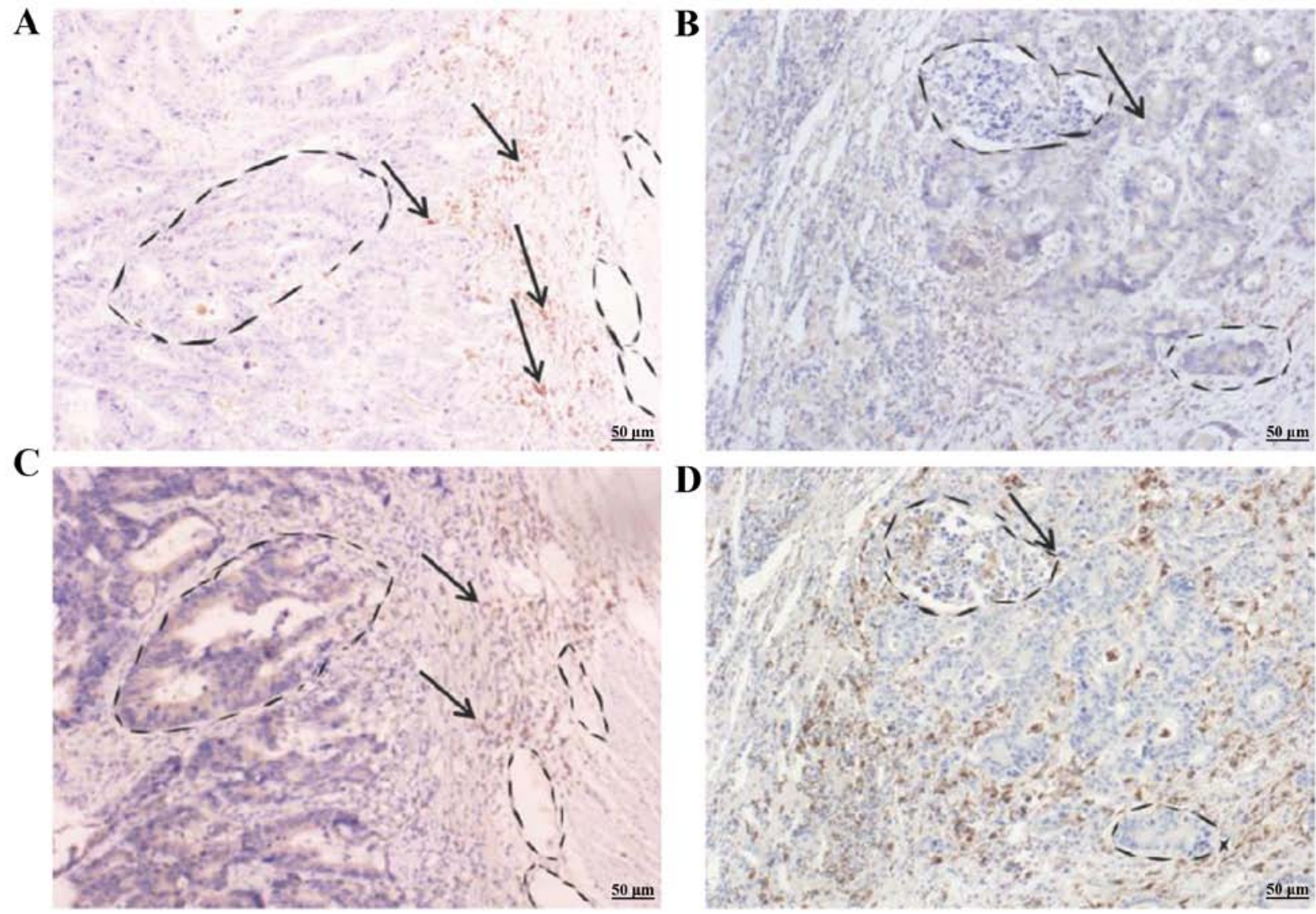

Figure 2. Differential expression of $\alpha 7 \mathrm{nAChR}$ and CD68 in the stroma of the primary colonic adenocarcinomas of colorectal cancer (CRC) patients. Patient A with Dukes' A classification shows strong staining of (A) $\alpha 7 \mathrm{nAChR}$ and (C) CD68 in paired representative sections of CRC. Patient B with Dukes' D classification shows (B) weak staining of $\alpha 7 \mathrm{nAChR}$, but (D) strong staining of CD68 in paired representative sections of CRC. Arrows indicate the stained $\alpha 7 \mathrm{nAChR}$ and CD68 in the stroma of CRC patient tissues, respectively.

Indirect co-culture of LoVo cells and TMs. To obtain TAMs, the indirect co-culture of $\mathrm{TM} \alpha 7^{-/}$and TM with CRC LoVo cells was achieved using a Transwell co-culture system (0.4- $\mu \mathrm{m}$ pore size; Corning) in 6 -well tissue culture plates. In brief, $2 \times 10^{5}$ of LoVo cells in $1.6 \mathrm{ml}$ of culture medium were seeded in the upper side of the membrane of the Transwell. Transwell inserts were then placed into 6-well plates cultured with $1 \times 10^{6}$ of $\mathrm{TM} \alpha 7^{-/-}$or TM cells in $2.5 \mathrm{ml}$ of culture medium. The polycarbonate Transwell membrane with $0.4-\mu \mathrm{m}$ pores allows the exchange of the medium but limits the cell-cell interactions between the cancer cells and macrophages.

Western blotting. Cells were lysed in 1X RIPA buffer from Cell Signaling Technology (CST; Danvers, MA, USA) containing $1 \mathrm{mM}$ phenylmethylsulfonyl fluoride (PMSF) and a protease inhibitor cocktail. The protein concentration was determined by Bradford protein assay. Total proteins $(40 \mu \mathrm{g})$ were separated by SDS-PAGE and blotted onto PVDF membranes. The blots were first probed by antibodies against different phosphorylated proteins including phospho-STAT3, phospho-PI3 kinase p85, phospho-NF- $\mathrm{B}$ p65, and $\beta$-actin. All the antibodies were bought from Cell Signaling Technology (CST). Then the membranes were probed with a horseradish peroxidase-conjugated goat anti-rabbit secondary antibody (Lianke, Hangzhou, China) followed by the detection of signals with FluorChem E system (Protein Simple, Santa Clara, CA, USA).
Statistical analysis. All assays were performed in triplicate. Data were analyzed using Stata 9.1 (Stata Corp., College Station, TX, USA) and presented as the mean \pm SD. Significance of differences between clinical groups was determined by Chi-squared test and the invasion/migration data were determined by Student's t-test. A p-value $<0.05$ was considered to be statistically significant.

\section{Results}

$\alpha 7 n A C h R$ in TAMs prevents hepatic metastasis in CRC patients. We first determined the expression of CD68 in primary colonic adenocarcinoma of 51 colorectal patients using IHC staining as this intracellular glycoprotein is tightly associated with TAMs $(31,32)$. As shown in Fig. 2, CD68 was highly expressed in tumorous stroma, especially, in invasive cells of 2 representative colonic adenocarcinomas (Fig. 2C and D). We then determined whether $\alpha 7 \mathrm{nAChR}$ was expressed in TAMs in $51 \mathrm{CRC}$ patients using IHC staining. Expression of $\alpha 7 \mathrm{nAChR}$ paralleled with CD68 in primary colonic adenocarcinoma of the 2 representative patients (Fig. $2 \mathrm{~A}$ and $\mathrm{B}$ ). We classified the $\alpha 7 \mathrm{nAChR}$ expression in TAMs into 5 grades (0-4) based on the $\alpha 7 \mathrm{nAChR}$ intensity detected. Grade 0 indicated no expression of $\alpha 7 \mathrm{nAChR}$, grade 1 only had weak $\alpha 7 \mathrm{nAChR}$ expression while grade 2 to 4 exhibited medium to strong expression of $\alpha 7 \mathrm{nAChR}$. The results revealed that $33 \mathrm{CRC}$ patients $(64.7 \%)$ had grade 0 or $1 \alpha 7 \mathrm{nAChR}$ expression. Fourteen patients 
A

a

TM

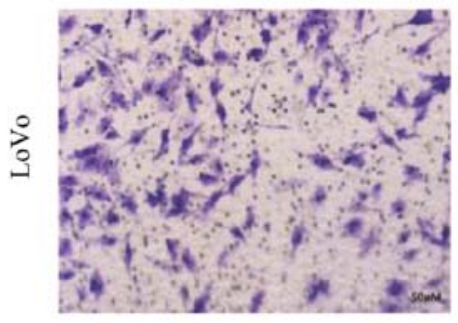

B

a TM

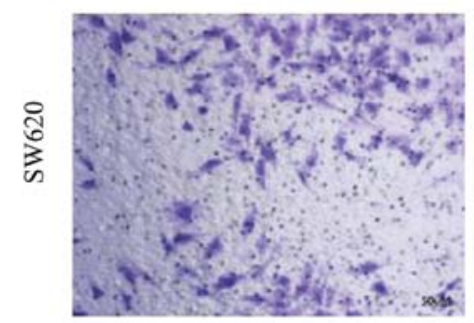

b

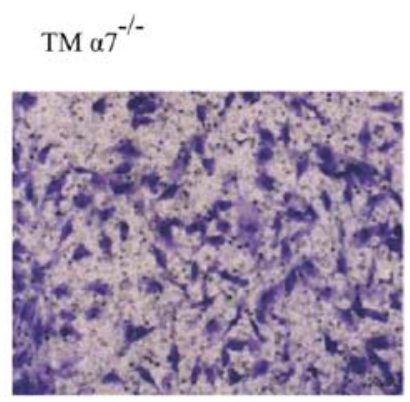

C

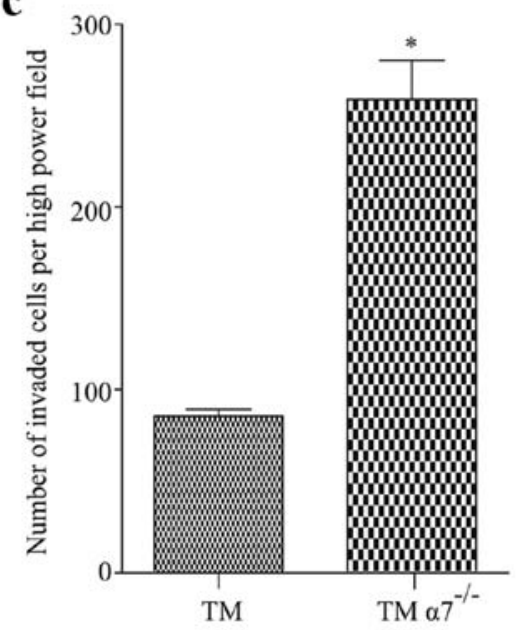

C

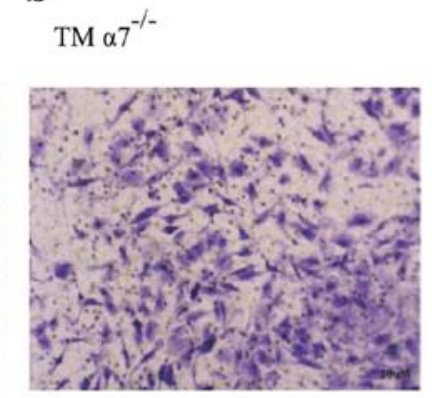

b

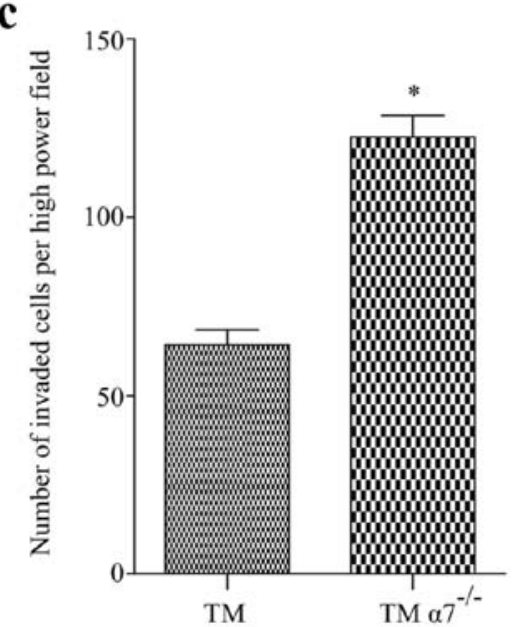

Figure 3. Knockdown of $\alpha$ 7nAChR in THP-1 derived macrophages (TMs) promotes colorectal cancer (CRC) cell migration in vitro. (A) LoVo or (B) SW620 cells were plated in the top chamber of $8 \mu \mathrm{m}$ polycarbonate membranes. Cell migration in response to (a) TM or (b) TM $\alpha^{-/ 2}$ was analyzed after $36 \mathrm{~h}$ (for LoVo) or $24 \mathrm{~h}$ (for SW620). Representative images are shown. The number of migrated CRC cells are presented as the mean \pm SD of six images of three experiments $(\mathrm{n}=3, \mathrm{c})$. Significance of differences between groups was determined by Student's t-test. A p-value $<0.05$ was considered to be statistically significant. The asterisk symbol indicates statistically significant differences between TM and TM $\alpha 7^{-1-}$ cells $(\mathrm{p}=0.007$ for LoVo and 0.0004 for SW620, respectively).

(42.4\%) had a 5-year survival. Eighteen patients $(35.3 \%)$ had grade 2 to 4 expression (Table I). Notably, the other 18 patients who exhibited grade 2-4 expression of $\alpha 7 \mathrm{nAChR}$ had a 5-year survival at $77.8 \%$, which is statistically significant. We observed that 14 of the 51 CRC patients $(27.5 \%)$ with Dukes' D classification had hepatic metastasis. Among these 14 patients, 13 had grade 0 or $1 \alpha 7 \mathrm{nAChR}$ expression and only 1 had grade $2 \alpha 7 n$ AChR expression. The other 37 patients (72.5\%) with Dukes' A to C classification did not have hepatic metastasis. In this 37-patient group, 20 had grade 0 or 1 $\alpha 7 \mathrm{nAChR}$ expression and 17 had grade 2 to 4 , respectively. Our results indicated that most of the hepatic metastatic CRC patients had low expression of $\alpha 7 \mathrm{nAChR}$ (grade 0 to 1 ) while non-metastatic patients exhibited strong expression of $\alpha 7 n$ AChR. Statistically the difference between the patient groups was significant, suggesting that $\alpha 7 \mathrm{nAChR}$ may play a functional role in the prevention of CRC metastasis.

Knockdown of $\alpha 7 n A C h R$ in TMs promotes CRC cell migration and invasion in vitro. To demonstrate our clinical observations that $\alpha 7 \mathrm{nAChR}$ expressed in TAMs may play a role in preventing $\mathrm{CRC}$ metastasis, we investigated the migration and invasion of CRC cells in a CRC/TM co-culture model. Two CRC cell lines LoVo and SW620 were co-cultured with THP-1 derived macrophages with or without $\alpha 7 \mathrm{nAChR}$ knockdown (TM and $\mathrm{TM} \alpha 7^{-/}$), respectively. The results revealed that both CRC cell lines co-cultured with TMs only had a few migrated or invaded cells after a certain period (Figs. 3 and 4). In contrast, the number of migrated or invaded CRC cells were significantly increased in the co-cultured with $\mathrm{TM} \alpha 7^{-/-} \mathrm{CRC}$ cell lines (Figs. 3 and 4), demonstrating that $\alpha 7 n A C h R$ may play an important role in cancer cell migration and invasion in vitro.

$\alpha 7 n A C h R$ regulates the expression of phosphorylated STAT3, PI3K p85 and NF- $\kappa B$ p65 in TAMs. Next, we determined whether $\alpha 7 \mathrm{nAChR}$ had any regulatory roles in the expression and functions of key signaling molecules in both TAM and TAM $\alpha 7^{-/ 2}$. TM and TM $\alpha 7^{-/-}$cells were indirectly co-cultured with LoVo cells and then expressions of three key signaling 
A

a

$\mathrm{TM}$

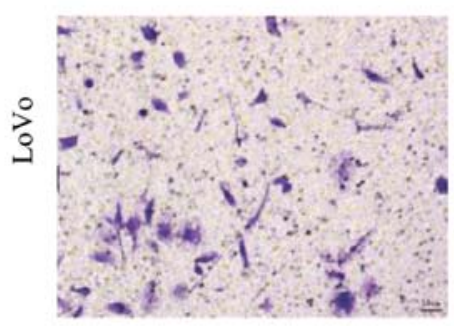

B

a

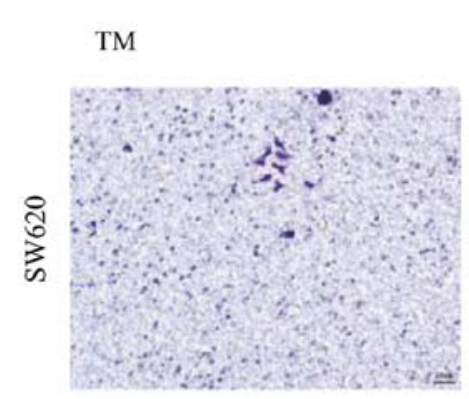

b

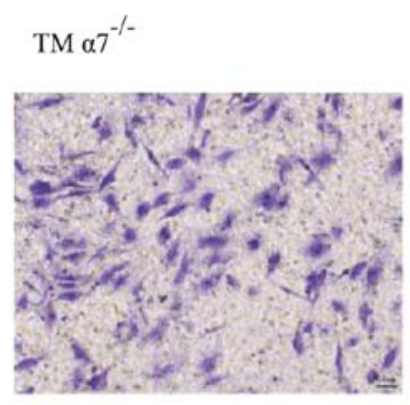

b

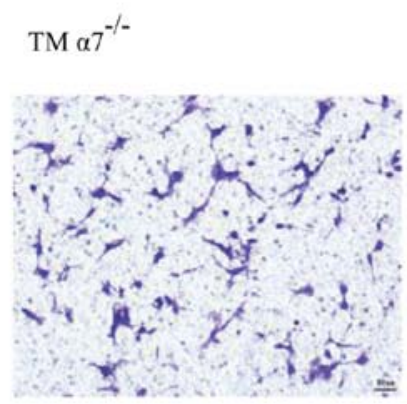

c

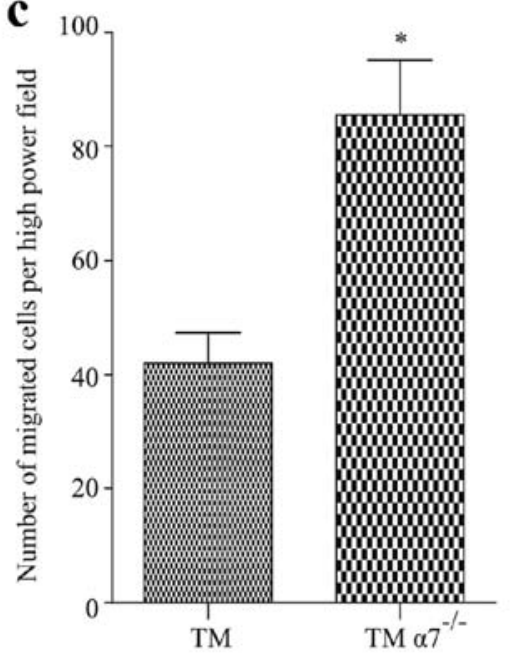

c

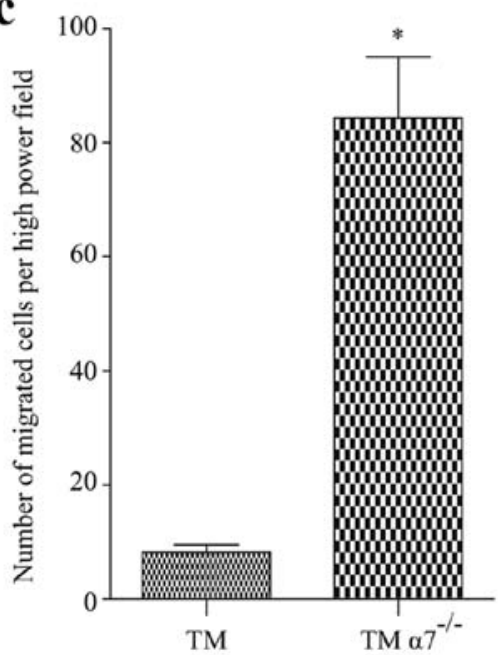

Figure 4. Knockdown of $\alpha 7 \mathrm{nAChR}$ in THP-1 derived macrophages (TMs) promotes colorectal cancer (CRC) cell invasion in vitro. (A) LoVo or (B) SW620 cells were co-cultured with either (a) TM or (b) TM T $^{-1-}$ in 24-well Transwell plates with 8- $\mu \mathrm{m}$ polycarbonate membrane filters coated with $100 \mu \mathrm{l}$ of Matrigel. After $36 \mathrm{~h}$ (for LoVo) or $24 \mathrm{~h}$ (for SW620) co-culture, the cells that invaded to the lower surface through the Matrigel were fixed, stained and quantitated by cell counting under a light microscope in four predetermined fields at a magnification of x400.Representative images are shown. The number of invaded CRC cells are presented as the mean \pm SD of six images of three separate experiments $(n=3$, c). Significance of differences between groups was determined by Student's t-test. A p-value $<0.05$ was considered to be statistically significant. The asterisk symbol indicates statistically significant differences between TM and $\mathrm{TM} \alpha 7^{-/}$cells $(\mathrm{p}=0.0002$ for both cells).

molecules [phosphorylated-STAT3 (p-STAT3), phosphorylated-PI3K p85 (p-PI3K p85) and phosphorylated-NF- $\mathrm{B}$ p65 (p-NF-kB p65)] were detected by western blotting. As shown in Fig. 5, results revealed that knockdown of $\alpha 7 \mathrm{nAChR}$ in TMs significantly inhibited the expression of p-STAT3, p-PI3K p85 and p-NF- $\kappa \mathrm{B}$ p65 after co-culturing with LoVo cells. The data revealed that $\alpha 7 \mathrm{nAChR}$ may play a crucial role in the regulation of the expression of p-STAT3, p-PI3K and p-NF- $\mathrm{B}$ in macrophages, which are involved in the metastasis of cancer cells.

Inhibition of phosphorylated-STAT3 in TMs prevents cancer cell migration. To determine whether the expression of p-STAT3, p-PI3K and p-NF- $\kappa$ B regulated by $\alpha 7 n$ AChR in TMs may mediate CRC cell migration, we first treated TMs with or without a potent nicotinic $\alpha 7$ receptor antagonist: $\alpha$-Btx for $6 \mathrm{~h}$ and then with three inhibitors: AG490 (JAK2/STAT3 inhibitor), LY294002 (PI3K inhibitor) and Bay 11-7082 (NF-кB inhibitor) for $1 \mathrm{~h}$, respectively. The inhibitor-treated TMs after being washed with PBS were co-cultured with CRC cells (LoVo cells) for $36 \mathrm{~h}$ to determine the migration of LoVo cells. The results clearly revealed that a very low number of LoVo cells had migrated when they were co-cultured with TMs under the condition that TMs were treated only with AG490, LY294002 and Bay 11-7082 [Fig. 6A (upper panel) and B)]. In contrast, the number of migrated LoVo cells was significantly increased when TMs were only treated $\alpha$-Btx (Fig. 6). These results further demonstrated that $\alpha 7 \mathrm{nAChR}$ expressed in TMs prevented CRC cell migration as shown in Fig. 4. Furthermore, the number of migrated LoVo cells was also markedly increased when TMs were dually treated with $\alpha$-Btx and either LY294002 or Bay 11-7082, suggesting that the PI3K and NF- $\mathrm{B}$ signaling pathway is not involved in $\alpha 7 \mathrm{nAChR}-$ mediated migration of CRC cells. Conversely, dual treatment of $\alpha$-Btx and AG 490 substantially prevented the migration of CRC cells (Fig. 6), suggesting that $\alpha 7 n \mathrm{AChR}$ 


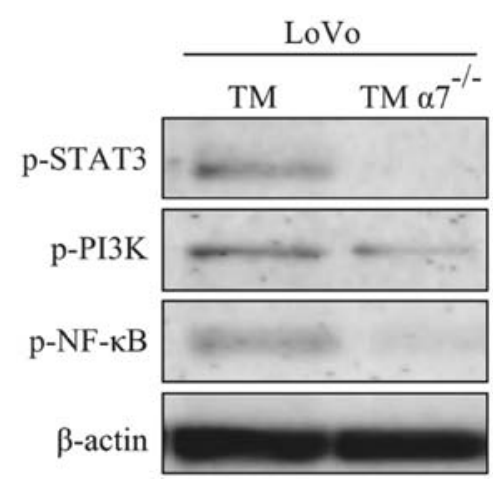

Figure 5. $\alpha 7 \mathrm{nAChR}$ regulates the expression of phosphorylated STAT3, PI3Kp85 and NF- $\mathrm{KB}$ p65 in tumor-associated macrophages (TAMs). THP-1 derived macrophages (TMs) and $\mathrm{TM} \alpha 7^{-\digamma}$ at $1 \times 10^{6}$ cells were indirectly co-cultured with LoVo cells for $24 \mathrm{~h}$. TMs were then harvested for western blotting to determine the expression of phosphorylated STAT3, PI3Kp85 and $\mathrm{NF}-\mathrm{kB}$ p65. Results are representative of three independent experiments.

expressed in TMs inhibits the migration of CRC cells through the JAK2/STAT3 signaling pathway.

\section{Discussion}

Metastasis is a multistep process by which cancer cells disseminate from primary tumors and establish secondary lesions in distant organs (33). The liver is one of the most significant targets for organ-specific metastasis in various cancer types and is commonly the sole site of metastasis for CRC (34). Hepatic metastasis (e.g., liver metastasis) is an ominous event in the natural history and progression of CRC (35), which is a major cause of mortality in CRC patients. To date, the underlying mechanisms of the hepatic metastasis in CRC patients have not been fully elucidated. Also, few studies have been published which demonstrate that TAMs play a role in preventing hepatic metastasis. In the present study we first observed that TAMs with $\alpha 7 \mathrm{nAChR}$ expression are associated with less incidents of hepatic metastasis in CRC patients. Furthermore we observed that THP-derived macrophages with $\alpha 7 \mathrm{nAChR}$ knockdown $\left(\mathrm{TM} \alpha 7^{-/}\right)$significantly promoted the invasion and migration of two CRC cell lines in a two-cell Transwell co-culture model, similar to a previously published study which demonstrated that siRNA-knockdown of androgen receptor promotes
A

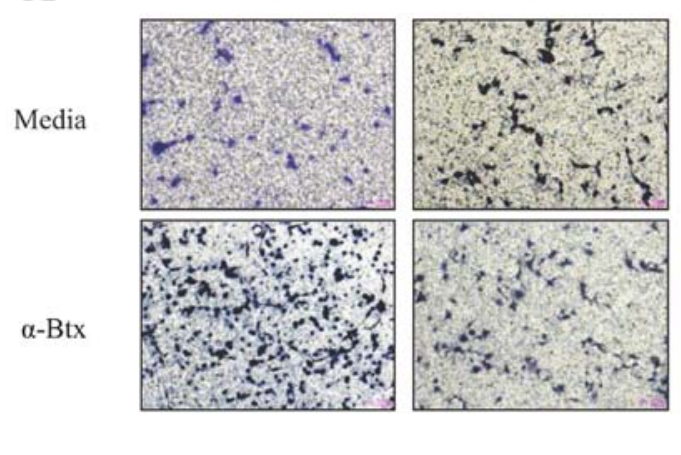

LY294002

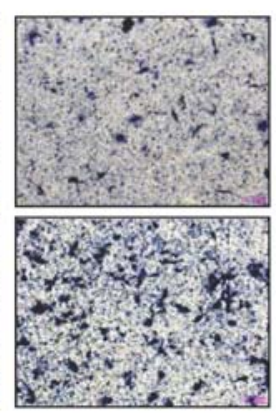

Bay 11-7082

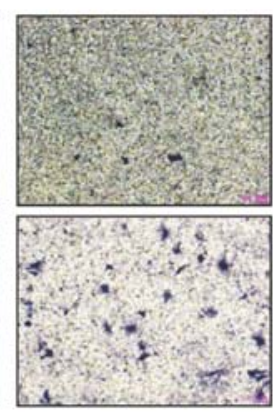

B

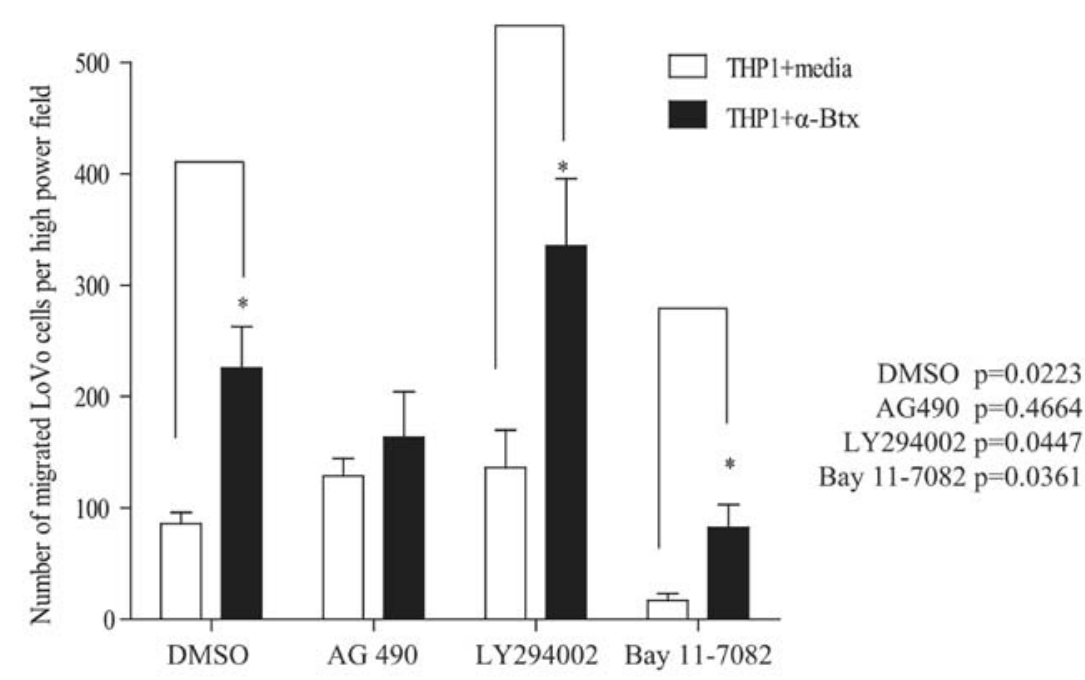

Figure 6. $\alpha 7 \mathrm{nAChR}$ expressed in THP-1 derived macrophages (TMs) inhibits the migration of CRC cells through the JAK2/STAT3 signaling pathway. TMs were treated with or without $\alpha$-bungarotoxin $(\alpha$-Btx) for $6 \mathrm{~h}$ and then with DMSO (control), AG490, LY294002 and Bay 11-7082 for 1 h, respectively. Subsequently, LoVo cells were co-cultured with TM in 24-well Transwell plates with $8 \mu$ m polycarbonate membrane filters for $36 \mathrm{~h}$ for the migration assay. (A) Upper panel: Representative images show the migration of LoVo cells under the condition that the TMs did not have the $\alpha$-Btx treatment and were treated with AG490, LY294002 and Bay 11-7082 only, respectively. Lower panel: Representative images show the migration of LoVo cells under the condition that the TMs were treated with $\alpha$-Btx only, or dually treated with AG490, LY294002 and Bay 11-7082, respectively. (B) Number of migrated LoVo cells are presented as the mean \pm SD of six images $(n=6)$ of three separate experiments. Significance of differences between groups was determined by Student's t-test. $\mathrm{P}$-value $<0.05$ indicates that there was a significant difference between treatments. 
prostate cancer metastasis through enhanced macrophage recruitment (36). Thus, our data from both in vivo and in vitro experiments revealed that $\alpha 7 \mathrm{nAChR}$ expressed in TAMs may play an important role in preventing metastasis and could be a prognosis marker in human CRCs.

Significant progress has been made in identifying the molecular basis for both macrophage phenotypes and their actions in promoting specific aspects of tumor behavior. A published study revealed that $\mathrm{NF}-\kappa \mathrm{B}$ activation is extremely crucial for mediating inflammation-induced tumor growth and progression, and modulating tumor surveillance and rejection (37).

It appeared that STAT3 activation was much more important for CRC growth and progression, and its surveillance and rejection in the present study.

Another study revealed that STAT3 is a point of convergence for numerous oncogenic signaling pathways, which is constitutively activated in both tumor cells and immune cells in the tumor microenvironment (38). The constitutive activation of STAT3 inhibits the expression of mediators necessary for immune activation against tumor cells and promotes the production of immunosuppressive factors leading the tumor to escape from host immune surveillance (38). Also, the invasive capacity of tumor cells can increase in the presence of inflammatory cytokines such as IL-1 $\beta$ and IL-6 (39). IL-6 is crucial for inducing and maintaining a cancer-promoting inflammatory environment and macrophage derived IL-6 promotes colorectal tumor cell survival and proliferation $(40,41)$. Kaler et al (42) reported that TAMs, through IL-1 $\beta$ production, promote Wnt signaling in colon cancer cells, supporting tumor growth. It has been demonstrated that in macrophages, STAT3 is crucial for regulating the expression of cytokines (43-47). Based on the aforementioned evidence, we hypothesized that IL- 6 and IL- $1 \beta$ may be the potential downstream molecules of the $\alpha 7 \mathrm{nAChR} / \mathrm{JAK} 2 / \mathrm{STAT} 3$ pathway in macrophages, which regulate CRC metastasis. In future studies, we will explore the molecular mechanism of this phenomenon.

In addition, Mantovani et al (48) reported that PI3K activation may be a universal requirement for macrophage M2 differentiation and activation which may play the pro-tumoral role. Our laboratory tried to find a potential signaling pathway that correlated macrophage $\alpha 7 \mathrm{nAChR}$ and CRC cell metastasis .

Activation of nAChRs in non-neuronal cells elicits the non-ionic signaling events that regulate protein phosphorylation and dephosphorylation, which is a novel function of $\mathrm{nAChR}$ subunit proteins in non-excitable cells. Activation of $\alpha 7 \mathrm{nAChR}$ can activate p38 MAPK, AKT, RAS/RAF/MEK/ERK and JAK2 $(49,50)$. In the present study, we determined the expression of phosphorylated STAT3, NF- $\kappa$ B p65 and PI3K p85 in THP-derived macrophages with or without $\alpha 7 \mathrm{nAChR}$ knockdown ( $\mathrm{TMa}^{-/-}$and TM). The results revealed that phosphorylation of STAT3 was undetectable in TM $\alpha 7^{-/-}$cells and NF- $\mathrm{BB}$ p 65 and PI3K p85 were faint after co-culturing with LoVo cells, suggesting that the STAT3, NF- $\kappa$ B and PI3K signaling pathways may be related with $\alpha 7 \mathrm{nAChR}$ expression. Furthermore, TMs treated with the $\alpha 7 \mathrm{nAChR}$ inhibitor $\alpha$-Btx increased $\mathrm{CRC}$ cell invasion/migration that was prevented by treatment of the JAK2/STAT3 inhibitor AG490. These results further demonstrated that $\alpha 7$ nicotinic $\mathrm{ACh}$ receptor in TAMs inhibits CRC metastasis through the JAK2/STAT3 signaling pathway.
Previously, de Jonge et al (51) reported that the anti-inflammatory action of the activated nicotinic receptor in peritoneal macrophages was associated with the activation of the transcription factor STAT3. It has been well established that STAT3 is a key transcription factor in both immunity and inflammatory pathways. Ablation in myeloid cells of Stat3, a transcription factor whose function suppresses inflammatory responses since it is a major target of immunosuppressive cytokine IL-10 (52), causes inflammation in the colon. In the present study, $\alpha 7 n$ AChR knockdown substantially inhibited the expression of phosphorylated STAT3 in macrophages, providing evidence that phosphorylation of STAT3 is essential for $\alpha 7 \mathrm{nAChR}$ to prevent functional invasion and migration of CRC cells although STAT3 is considered to be an oncogene that is frequently activated in a variety of human cancer cells and promotes the growth and survival of tumor cells $(53,54)$.

In the present study, we clinically observed that the expression of $\alpha 7 \mathrm{nAChR}$ in TAMs was associated with a low incidence of hepatic metastasis in CRC patients. We found that $\alpha 7 \mathrm{nAChR}$ knockdown in THP-derived macrophages (TMs) significantly enhanced the migration and invasion of CRC cells, which was regulated through the JAK2/STAT3 signaling pathway in in vitro experiments. Our results revealed that $\alpha 7 \mathrm{nAChR}$ expressed in TAMs may play an important role in preventing metastasis and could be a prognosis marker in CRCs. If validated in larger study sets, these findings may have potential clinical relevance since the detected cytokines and signaling proteins are current targets for molecularly-targeted therapeutics, leading to liver metastasis specific molecular therapies for the CRC.

\section{Acknowledgements}

The present study was supported by a grant from the Key Project of Natural Science Foundation of Zhejiang Province (LZ16H160003 to W.C.).

\section{References}

1. Coussens LM and Werb Z: Inflammation and cancer. Nature 420: 860-867, 2002

2. Allavena P, Sica A, Solinas G, Porta C and Mantovani A: The inflammatory micro-environment in tumor progression: The role of tumor-associated macrophages. Crit Rev Oncol Hematol 66: $1-9,2008$.

3. Siveen KS and Kuttan G: Role of macrophages in tumour progression. Immunol Lett 123: 97-102, 2009.

4. Pollard JW: Tumour-educated macrophages promote tumour progression and metastasis. Nat Rev Cancer 4: 71-78, 2004.

5. Pancione M, Giordano G, Remo A, Febbraro A, Sabatino L, Manfrin E, Ceccarelli M and Colantuoni V: Immune escape mechanisms in colorectal cancer pathogenesis and liver metastasis. J Immunol Res 2014: 686879, 2014.

6. Mantovani A, Bottazzi B, Colotta F, Sozzani S and Ruco L: The origin and function of tumor-associated macrophages. Immunol Today 13: 265-270, 1992.

7. Kruse J, von Bernstorff W, Evert K, Albers N, Hadlich S, Hagemann S, Günther C, van Rooijen N, Heidecke CD and Partecke LI: Macrophages promote tumour growth and liver metastasis in an orthotopic syngeneic mouse model of colon cancer. Int J Colorectal Dis 28: 1337-1349, 2013.

8. Nakayama Y, Nagashima N, Minagawa N, Inoue Y, Katsuki T, Onitsuka K, Sako T, Hirata K, Nagata N and Itoh H: Relationships between tumor-associated macrophages and clinicopathological factors in patients with colorectal cancer. Anticancer Res 22: 4291-4296, 2002. 
9. Zhou Q, Peng RQ, Wu XJ, Xia Q, Hou JH, Ding Y, Zhou QM, Zhang X, Pang ZZ, Wan DS, et al: The density of macrophages in the invasive front is inversely correlated to liver metastasis in colon cancer. J Transl Med 8: 13, 2010.

10. Ishimaru E, Imano M, Okuno K, Shiozaki $H$ and Ohyanagi $H$ : Local Existence of Osteopontin Positive Tumor-Associated Macrophages in Colorectal Cancer Stroma as Risk Factors of Postoperative Hepatic Metastasis. Jpn J Gastroenterol Surg 40: 695-704, 2007.

11. Kinouchi M, Miura K, Mizoi T, Ishida K, Fujibuchi W, Sasaki H, Ohnuma S, Saito K, Katayose Y, Naitoh T, et al: Infiltration of CD40-positive tumor-associated macrophages indicates a favorable prognosis in colorectal cancer patients. Hepatogastroenterology 60: 83-88, 2013.

12. Egleton RD, Brown KC and Dasgupta P: Nicotinic acetylcholine receptors in cancer: Multiple roles in proliferation and inhibition of apoptosis. Trends Pharmacol Sci 29: $151-158,2008$.

13. Shi D, Guo W, Chen W, Fu L, Wang J, Tian Y, Xiao X, Kang T, Huang W and Deng W: Nicotine promotes proliferation of human nasopharyngeal carcinoma cells by regulating $\alpha 7 \mathrm{AChR}, \mathrm{ERK}$, HIF-1 $\alpha$ and VEGF/PEDF signaling. PLoS One 7: e43898, 2012.

14. Dasgupta P, Rastogi S, Pillai S, Ordonez-Ercan D, Morris M, Haura $E$ and Chellappan S: Nicotine induces cell proliferation by $\beta$-arrestin-mediated activation of Src and Rb-Raf-1 pathways. J Clin Invest 116: 2208-2217, 2006.

15. Dasgupta P, Rizwani W, Pillai S, Davis R, Banerjee S, Hug K, Lloyd M, Coppola D, Haura E and Chellappan SP: ARRB1-mediated regulation of E2F target genes in nicotine-induced growth of lung tumors. J Natl Cancer Inst 103: 317-333, 2011.

16. Lin W, Hirata N, Sekino Y and Kanda Y: Role of $\alpha 7$-nicotinic acetylcholine receptor in normal and cancer stem cells. Curr Drug Targets 13: 656-665, 2012

17. Papke RL, Bagdas D, Kulkarni AR, Gould T, AlSharari SD, Thakur GA and Damaj MI: The analgesic-like properties of the alpha7 nAChR silent agonist NS6740 is associated with non-conducting conformations of the receptor Neuropharmacology 91: 34-42, 2015.

18. Arias HR, Richards VE, Ng D, Ghafoori ME, Le V and Mousa SA: Role of non-neuronal nicotinic acetylcholine receptors in angiogenesis. Int J Biochem Cell Biol 41: 1441-1451, 2009.

19. Russo P and Taly A: $\alpha 7$-nicotinic acetylcholine receptors: An old actor for new different roles. Curr Drug Targets 13: 574-578, 2012.

20. 20. Di Paolo G and Kim T-W: Linking lipids to Alzheimer's disease: Cholesterol and beyond. Nat Rev Neurosci 12: 284-296, 2011.

21. Wang H, Yu M, Ochani M, Amella CA, Tanovic M, Susarla S, Li JH, Wang H, Yang H, Ulloa L, et al: Nicotinic acetylcholine receptor alpha7 subunit is an essential regulator of inflammation. Nature 421: 384-388, 2003

22. Gallowitsch-Puerta $M$ and Pavlov VA: Neuro-immune interactions via the cholinergic anti-inflammatory pathway. Life Sci 80: 2325-2329, 2007.

23. Russo P, Del Bufalo A, Milic M, Salinaro G, Fini M and Cesario A: Cholinergic receptors as target for cancer therapy in a systems medicine perspective. Curr Mol Med 14: 1126-1138, 2014.

24. Dinicola S, Morini V, Coluccia P, Proietti S, D'Anselmi F, Pasqualato A, Masiello MG, Palombo A, De Toma G, Bizzarri M, et al: Nicotine increases survival in human colon cancer cells treated with chemotherapeutic drugs. Toxicol In Vitro 27: 2256-2263, 2013.

25. Xiang T, Fei R, Wang Z, Shen Z, Qian J and Chen W: Nicotine enhances invasion and metastasis of human colorectal cancer cells through the nicotinic acetylcholine receptor downstream p38 MAPK signaling pathway. Oncol Rep 35: 205-210, 2016.

26. Nieh S, Jao SW, Yang CY, Lin YS, Tseng YH, Liu CL, Lee TY, Liu TY, Chu YH and Chen SF: Regulation of tumor progression via the Snail-RKIP signaling pathway by nicotine exposure in head and neck squamous cell carcinoma. Head Neck: 1712-1721, 2015.

27. Zovko A, Viktorsson K, Lewensohn R, Kološa K, Filipič M, Xing H, Kem WR, Paleari L and Turk T: APS8, a polymeric alkylpyridinium salt blocks $\alpha 7 \mathrm{nAChR}$ and induces apoptosis in non-small cell lung carcinoma. Mar Drugs 11: 2574-2594, 2013.
28. Salaga M, Blomster LV, Piechota-Polańczyk A, Zielińska M, Jacenik D, Cygankiewicz AI, Krajewska WM, Mikkelsen JD and Fichna J: Encenicline, an $\alpha 7$ nicotinic acetylcholine receptor partial agonist, reduces immune cell infiltration in the colon and improves experimental Colitis in mice. J Pharmacol Exp Ther 356: 157-169, 2016.

29. Compton CC, Fielding LP, Burgart LJ, Conley B, Cooper HS, Hamilton SR, Hammond ME, Henson DE, Hutter RV, Nagle RB, et al: Prognostic factors in colorectal cancer. College of American Pathologists Consensus Statement 1999. Arch Pathol Lab Med 124: 979-994, 2000.

30. Forssell J, Oberg A, Henriksson ML, Stenling R, Jung A and Palmqvist R: High macrophage infiltration along the tumor front correlates with improved survival in colon cancer. Clin Cancer Res 13: 1472-1479, 2007.

31. Saito N, Pulford KA, Breton-Gorius J, Massé JM, Mason DY and Cramer EM: Ultrastructural localization of the CD68 macrophage-associated antigen in human blood neutrophils and monocytes. Am J Pathol 139: 1053-1059, 1991.

32. Kurahara H, Shinchi H, Mataki Y, Maemura K, Noma H, Kubo F, Sakoda M, Ueno S, Natsugoe S and Takao S: Significance of M2-polarized tumor-associated macrophage in pancreatic cancer. J Surg Res 167: e211-e219, 2011.

33. Jin K, Gao W, Lu Y, Lan H, Teng L and Cao F: Mechanisms regulating colorectal cancer cell metastasis into liver (Review) Oncol Lett 3: 11-15, 2012.

34. Nguyen DX, Bos PD and Massagué J: Metastasis: From dissemination to organ-specific colonization. Nat Rev Cancer 9: 274-284, 2009.

35. Rudmik LR and Magliocco AM: Molecular mechanisms of hepatic metastasis in colorectal cancer. J Surg Oncol 92: 347-359, 2005.

36. Izumi K, Fang LY, Mizokami A, Namiki M, Li L, Lin WJ and Chang C: Targeting the androgen receptor with siRNA promotes prostate cancer metastasis through enhanced macrophage recruitment via CCL2/CCR2-induced STAT3 activation. EMBO Mol Med 5: 1383-1401, 2013.

37. Karin M and Greten FR: NF-kappaB: Linking inflammation and immunity to cancer development and progression. Nat Rev Immunol 5: 749-759, 2005.

38. Yu H, Kortylewski M and Pardoll D: Crosstalk between cancer and immune cells: Role of STAT3 in the tumour microenvironment. Nat Rev Immunol 7: 41-51, 2007.

39. Balkwill F, Charles KA and Mantovani A: Smoldering and polarized inflammation in the initiation and promotion of malignant disease. Cancer Cell 7: 211-217, 2005.

40. Mantovani A, Allavena P, Sica A and Balkwill F: Cancer-related inflammation. Nature 454: 436-444, 2008.

41. Erreni M, Mantovani A and Allavena P: Tumor-associated macrophages (TAM) and inflammation in colorectal cancer. Cancer Microenviron 4: 141-154, 2011.

42. Kaler P, Godasi BN, Augenlicht L and Klampfer L: The $\mathrm{NF}-\kappa \mathrm{B} / \mathrm{AKT}$-dependent induction of Wnt signaling in colon cancer cells by macrophages and IL-1 $\beta$. Cancer Microenviron 2: 69-80, 2009.

43. Cheng F, Wang HW, Cuenca A, Huang M, Ghansah T, Brayer J, Kerr WG, Takeda K, Akira S, Schoenberger SP, et al: A critical role for Stat3 signaling in immune tolerance. Immunity 19: 425-436, 2003.

44. Wang T, Niu G, Kortylewski M, Burdelya L, Shain K, Zhang S, Bhattacharya R, Gabrilovich D, Heller R, Coppola D, et al: Regulation of the innate and adaptive immune responses by Stat-3 signaling in tumor cells. Nat Med 10: 48-54, 2004.

45. Ogura H, Murakami M, Okuyama Y, Tsuruoka M, Kitabayashi C, Kanamoto M, Nishihara M, Iwakura Y and Hirano T: Interleukin-17 promotes autoimmunity by triggering a positive-feedback loop via interleukin-6 induction. Immunity 29 : 628-636, 2008

46. Kujawski M, Kortylewski M, Lee H, Herrmann A, Kay H and Yu H: Stat 3 mediates myeloid cell-dependent tumor angiogenesis in mice. J Clin Invest 118: 3367-3377, 2008.

47. Takeda K, Clausen BE, Kaisho T, Tsujimura T, Terada N, Förster I and Akira S: Enhanced Th1 activity and development of chronic enterocolitis in mice devoid of Stat 3 in macrophages and neutrophils. Immunity 10: 39-49, 1999.

48. Mantovani A, Sica A and Locati M: Macrophage polarization comes of age. Immunity 23: 344-346, 2005.

49. Grando SA: Connections of nicotine to cancer. Nat Rev Cancer 14: 419-429, 2014 
50. Xiang T, Yu F, Fei R, Qian J and Chen W: CHRNA7 inhibits cell invasion and metastasis of LoVo human colorectal cancer cells through PI3K/Akt signaling. Oncol Rep 35: 999-1005, 2016.

51. de Jonge WJ, van der Zanden EP, The FO, Bijlsma MF, van Westerloo DJ, Bennink RJ, Berthoud HR, Uematsu S, Akira S, van den Wijngaard RM, et al: Stimulation of the vagus nerve attenuates macrophage activation by activating the Jak2-STAT3 signaling pathway. Nat Immunol 6: 844-851, 2005.

52. Qian BZ and Pollard JW: Macrophage diversity enhances tumor progression and metastasis. Cell 141: 39-51, 2010.
53. Niu G, Bowman T, Huang M, Shivers S, Reintgen D, Daud A, Chang A, Kraker A, Jove R and Yu H: Roles of activated Src and Stat3 signaling in melanoma tumor cell growth. Oncogene 21: 7001-7010, 2002.

54. Xin H, Zhang C, Herrmann A, Du Y, Figlin R and $\mathrm{Yu} \mathrm{H}$ Sunitinib inhibition of Stat3 induces renal cell carcinoma tumor cell apoptosis and reduces immunosuppressive cells. Cancer Res 69: 2506-2513, 2009. 